\title{
Microcefalia asociada a la infección por virus del Zika en el periodo gestacional
}

\section{Microcephaly associated to Zika virus infection during pregnancy}

\author{
Ricardo Ávila-Reyes ${ }^{1 *}$, Trinidad López-Vega ${ }^{2}$, Rocío I. Camacho-Ramírez ${ }^{1}$, \\ Gabriela C. Constantino-López ${ }^{2}$, Laura E. Gutiérrez-Méndez ${ }^{2}$ y Nora I. Velázquez-Quintana ${ }^{1}$ \\ ${ }^{1}$ Hospital Infantil de Tamaulipas, Ciudad Victoria; ${ }^{2}$ Hospital General de Ciudad Mante Dr. Emilio Martínez Manautou, Ciudad Mante. Tamaulipas, México
}

\begin{abstract}
Background: In Mexico, the first autochthonous case of Zika virus (ZIKV) infection was detected in October 2015. The clinical manifestations are variable and $80 \%$ of infections are asymptomatic. We studied the relationship of microcephaly with ZIKV infection during pregnancy. Methods: Comparative study in neonates of mothers with laboratory-confirmed Zika during pregnancy (cases) and neonates whose mothers did not have confirmed Zika infection during pregnancy (controls). ZIKV infection was confirmed by detection of viral RNA by real-time reverse transcription polymerase chain reaction. Results: We detected 69 cases; the control group consisted of 138 neonates. Comparison of somatometry showed differences only in height $(p<0.05)$. Microcephaly was present in 7 neonates whose mothers had Zika and in 5 cases in the control group. Discussion: The prevalence of microcephaly was $10 \%$. The odds ratio (OR) for microcephaly was 3 in neonates exposed to ZIKV. The OR for microcephaly associated to Zika infection in the first semester of pregnancy was 12 . There were anatomical alterations in brains of Zika-exposed neonates without microcephaly; therefore, transfontanellar ultrasound should be performed in all newborns of mothers infected with ZIKV during pregnancy.
\end{abstract}

Key words: Microcephaly. Zika virus. Flavivirus. Newborn.

\section{Resumen}

Introducción: En octubre del 2015 se identificó el primer caso autóctono de zika en México. Las manifestaciones clínicas son variables y el $80 \%$ de los infectados suelen cursar asintomáticos. Se buscó la relación entre microcefalia e infección por virus del Zika (ZIKV) durante la gestación. Métodos: Estudio comparativo en neonatos de madres con Zika durante la gestación confirmada por laboratorio (casos) y neonatos cuyas madres no tuvieron infección por Zika en la gestación (controles). La infección por ZIKV fue confirmada por detección de ARN viral mediante reacción en cadena de la polimerasa con transcriptasa inversa en tiempo real. Resultados: Se identificaron 69 casos y el grupo control incluyó 138 neonatos. Al comparar la somatometría se encontraron diferencias solamente en estatura ( $p<0.05)$. Se presentó microcefalia en 7 neonatos cuyas madres tuvieron Zika y en 5 del grupo control. Discusión: La prevalencia de microcefalia fue del 10\%. La razón de momios (odds ratio, OR) para microcefalia fue de 3 en los neonatos

\section{Correspondence:}

*Ricardo Ávila-Reyes

E-mail: avilareyes@hotmail.com
Date of reception: 15-05-2019

Date of acceptance: 21-10-2019

DOI: $10.24875 / H M C M .19000208$
Available online: $02-04-2020$ Hosp Med Clin Manag. 2020;13:7-12

2604-0018 / @ 2019 Mexican Regional Hospitals of High Specialty and Federal Hospitals. Published by Permanyer. This is an open access article under the CC BY-NC-ND license (http://creativecommons.org/licenses/by-nc-nd/4.0/). 
expuestos a ZIKV. La OR para microcefalia asociada a infección por Zika en el primer semestre de gestación fue de 12. Se identificaron alteraciones anatómicas cerebrales en neonatos expuestos al ZIKV, pero sin microcefalia. La ausencia de microcefalia no excluye la afectación cerebral, por lo que debe realizarse ultrasonido transfontanelar a todo neonato cuya madre tuvo infección por ZIKV en la gestación.

Palabras clave: Microcefalia. Virus del Zika. Flavivirus. Recién nacido.

\section{INTRODUCCIÓN}

El virus del Zika (ZIKV) fue notificado por primera vez en América Latina a principios del 2015. Investigaciones clinicoepidemiológicas en el noreste de Brasil concluyeron que la infección por ZIKV durante la gestación se transmitía por vía uterina, provocando disrupción embrionaria y causando microcefalia y afectaciones graves en el desarrollo cerebral. EI ZIKV se transmite por la picadura de los mosquitos Aedes aegypti y Aedes albopictus hembras infectados con el virus, pero también se puede transmitir por vía sexual o en forma vertical durante la gestación ${ }^{1}$. El ZIKV pertenece al género Flavivirus y está relacionado con los virus de la fiebre amarilla, dengue, virus del Nilo Occidental y la encefalitis japonesa. Se han demostrado dos cepas por análisis genéticos: la africana y la asiática. Las epidemias relevantes por ZIKV han sido en 2007 en los Estados Federados de Micronesia, en 2013 en la Polinesia Francesa y recientemente, a principios del 2015, en Brasil se presentó el brote que se propagó en América Latina. En México, en octubre del 2015, se detectó el primer caso autóctono en el Estado de Nuevo León y el segundo se presentó en Chiapas; las muestras de ambos, procesadas en el Instituto de Diagnóstico y Referencia Epidemiológicos, resultaron positivas a ZIKV.

Los síntomas de esta enfermedad generalmente duran entre 4 y 7 días, y pueden confundirse con los del dengue. En algunos casos las manifestaciones clínicas son moderadas: fiebre $<39{ }^{\circ} \mathrm{C}$, dolor de cabeza, debilidad, dolor muscular y articular, inflamación en manos y pies, conjuntivitis no purulenta, edema en los miembros inferiores y exantema o erupción en la piel, de inicio en el rostro que se extiende por todo el cuerpo. Con menor frecuencia se presentan vómitos, diarrea, dolor abdominal y falta de apetito. Puede presentarse artritis, principalmente en pies y manos, que aparece entre 3 y 12 días después de la picadura de un mosquito infectado. Otros síntomas menores son dolor abdominal y vómito. La enfermedad generalmente es leve y autolimitada, con duración de 2 a 7 días. Sin embargo, se estima que
4 de cada 5 pacientes cursan asintomáticos, es decir, hasta el $80 \%$ de las infecciones por ZIKV podrían ser asintomáticas y autolimitadas ${ }^{2-4}$.

En Brasil, la infección por ZIKV se ha visto acompañada por un aumento de casos de microcefalia hasta 20 veces por arriba de sus registros históricos en regiones endémicas de ZIKV, por lo cual se ha considerado una posible relación de efecto teratogénico de esta nueva infección ${ }^{3}$. Aunque aún no se tiene clara la fisiopatología, hay reportes de detección viral en líquido amniótico y tejido cerebral fetal, habiendo descartado otras infecciones relacionadas con compromiso neurológico fetal, como los flavivirus de dengue, fiebre amarilla, virus del oeste del Nilo, virus de encefalitis transmitido por garrapatas, chicungunya y otros microrganismos del complejo TORCH (toxoplasma, otros, rubéola, citomegalovirus, Hepatitis). Por ello, se hace relevante la detección de partículas virales mediante microscopia electrónica en tejido cerebral fetal ya que, descartando otras infecciones relacionadas con daño neurológico, es muy probable que el ZIKV produzca daño neurológico severo. El riesgo mayor de afectación neurológica ocurre cuando la exposición es entre las semanas 14 y 17 de gestación ${ }^{3,5}$. La relación causa-efecto entre infección congénita con ZIKV y el daño neurológico no ha sido confirmada. Los efectos atribuidos a este, específicamente la microcefalia, deben evaluarse en forma sistémica, descartando otras posibles causas que generen la microcefalia. El Ministerio de Salud de Brasil estableció la investigación del vínculo de microcefalia con infección por ZIKV durante el embarazo, considerando como microcefalia a la circunferencia cefálica $\leq 2$ desviaciones estándar (DE) por debajo de la media para sexo y edad gestacional. En una cohorte de 35 niños con microcefalia, cuyas madres habían vivido o visitado áreas afectadas con ZIKV durante el embarazo, 25 (71\%) tenían microcefalia grave (circunferencia cefálica superior a 3 DE por debajo de la media para sexo y edad gestacional), 17 (49\%) tenían al menos una anormalidad neurológica y, de 27 niños sometidos a estudios por imágenes, todos presentaban anormalidades ${ }^{5}$. Por lo 
anterior, el presente estudio se diseñó para establecer la asociación de microcefalia en los neonatos hijos de madre con infección por ZIKV confirmada por laboratorio durante el periodo gestacional.

\section{MÉTODOS}

En el presente estudio comparativo, transversal y analítico se estudiaron a los recién nacidos en el periodo de septiembre de 2017 a agosto de 2018 en el Hospital General de Ciudad Mante, Tamaulipas. Se consideraron como casos a los neonatos cuyas madres tuvieron el antecedente de infección materna por ZIKV durante la gestación, confirmada esta por laboratorio mediante la detección de ARN viral por reacción en cadena de la polimerasa con transcriptasa inversa (RT-PCR) en tiempo real en muestras de suero tomadas en los primeros 5 días de inicio del cuadro clínico. A los casos se les tomaron las medidas biofísicas, peso, talla, perímetro cefálico (PC), semanas de gestación (SDG) al nacer (método de Capurro somático), y SDG al momento que la madre se infectó con el ZIKV. Se determinó microcefalia cuando el PC era $\leq 2 \mathrm{DE}$ respecto a su media para el sexo y edad gestacional tomando como referencia la tabla de crecimiento intrauterino ${ }^{6}$ de Olsen, et al. El grupo control fue el de los neonatos de la sala de alojamiento conjunto que se revisan al pase diario de visita. Se eligieron al azar por método no probabilístico por conveniencia hasta completar el número requerido para obtener el doble de los casos (138). Igualmente se registraron las medidas biofísicas: peso, talla, PC y SDG. Se consideró microcefalia en aquellos neonatos con $\mathrm{PC} \leq 2 \mathrm{DE}$ por debajo de la media para su edad gestacional y sexo. Durante el interrogatorio, las madres de este grupo control negaron haber cursado con algún proceso febril por dengue, Zika y/o chikunguña durante la gestación. Se evaluó que los casos no manifestaran clínicamente alguna cromosomopatía, malformación evidente y/o por clínica que no tuvieran infección por complejo TORCH, para incluirse en el estudio.

Para el análisis estadístico se emplearon pruebas comparativas de medias poblacionales: prueba de $T$ de Student no pareada y medidas de asociación en tablas de $2 \times 2$ para obtener la OR de microcefalia entre las pacientes, así como chi cuadrada en medidas no paramétricas tomando como nivel significativo $p<0.05$. Se usó el paquete estadístico SPSS $13^{\mathrm{TM}}$.
Tabla 1. Somatometría de los casos y controles y diferencias significativas

\begin{tabular}{lcccl}
\hline & $\mathbf{N}$ & Media & DE & $\mathbf{p}^{*}$ \\
\hline Peso Zika & 69 & 3.159 & .49 & NS \\
Peso control & 138 & 3.247 & .47 & \\
Talla Zika & 69 & 50.16 & 2.67 & $<0.05$ \\
Talla control & 138 & 47.78 & 3.28 & \\
PC Zika & 69 & 34.11 & 1.74 & NS \\
PC control & 138 & 34.19 & 1.67 & \\
SDG Zika & 69 & 38.43 & 1.57 & NS \\
SDG control & 138 & 38.54 & 1.87 & \\
\hline
\end{tabular}

"Prueba t de Student.

DE: desviación estándar; NS: no significativo; PC: perímetro cefálico; SDG: semanas de gestación.

\section{RESULTADOS}

Se identificaron 69 neonatos hijos de madre con antecedente de infección por ZIKV durante la gestación, $34(49.2 \%)$ del sexo masculino y $35(50.7 \%)$ del sexo femenino (Fig. 1). En el grupo de neonatos con exposición a ZIKV gestacional el peso promedio fue de $3,159 \mathrm{~g}$ (1,180-4,390 g; DE: 0.498). La talla promedio fue de $50.1 \mathrm{~cm}$ (43-56 cm; DE: 2.67). El PC promedio fue $34.1 \mathrm{~cm}$ (29-38 cm; DE: 1.74). El promedio de SDG al nacer fue de 38.4 (SDG: 34-41; DE: 1.57) (Tabla 1). El promedio del tiempo de infección por ZIKV en la madre fue a las 26 SDG. Los casos con microcefalia fueron $7 / 69(10.1 \%)$ (Tabla 1).

El grupo control consistió en 138 neonatos, 66 (47.8\%) del sexo masculino y 72 (52.2\%) del femenino (Fig. 1). El peso promedio fue de 3,247 g (2,110-4,450 g; DE: 0.47). La talla promedio fue de $47.8 \mathrm{~cm}(40-59 \mathrm{~cm}$; DE: 3.28). El PC promedio fue $34.1 \mathrm{~cm}(29-43 \mathrm{~cm}$; DE: 1.67$)$. Las SDG al nacer fueron de 38.54 en promedio (SDG: 34-44; DE: 1.87) (Tabla 1). Los casos de microcefalia en este grupo control fueron 5/138 (3.62\%) (Tabla 1).

En la tabla 2 se agrupan los datos descriptivos de los casos y controles y se muestra el comparativo de promedios poblacionales (prueba $\mathrm{t}$ ), en donde hubo diferencias significativas entre los casos de Zika y el grupo control, siendo estadísticamente significativa la mayor estatura de los casos.

En la tabla 3 se aprecia la OR en tabla de $2 \times 2$, teniendo resultado de probabilidad de 3 veces el presentarse microcefalia al nacer en los casos expuestos a ZIKV respecto a los controles. 


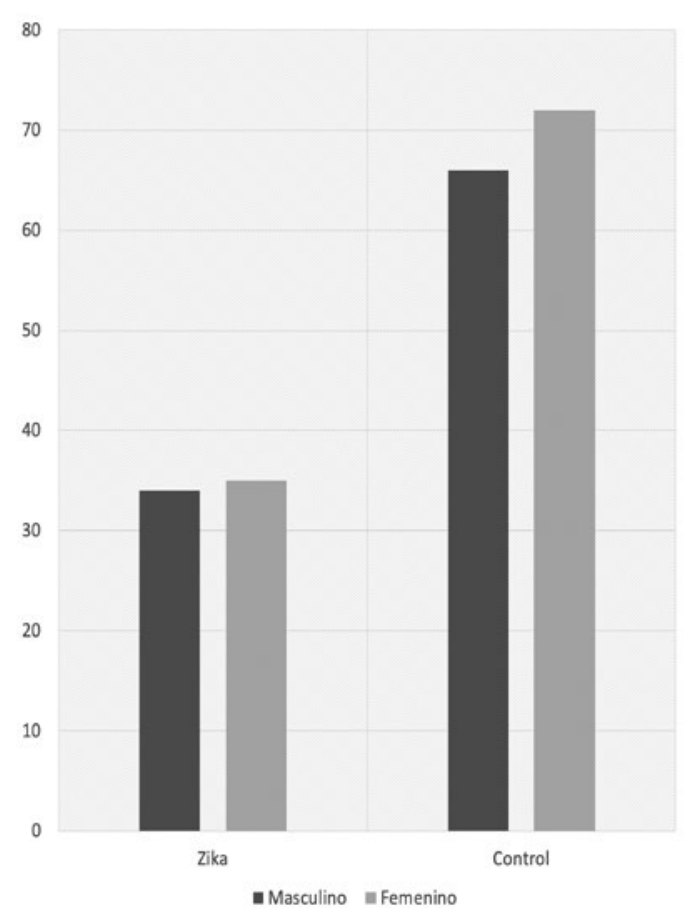

Figura 1. Distribución por sexo de los casos y controles.

A la mayoría de los casos de Zika (58/69) se les realizó ultrasonido, el cual fue normal en 50, 7 con ectasia leve de astas anteriores de los ventrículos laterales, 1 con agenesia de cuerpo calloso e hidrocefalia del tercer ventrículo y a 11 casos no se les realizó ultrasonido porque no acudieron a la cita. En la valoración oftalmológica se encontraron 62 casos normales, 4 con dacrioestenosis con fondo de ojo normal y 3 que no asistieron a la cita. El tamiz auditivo en 60 resultó normal y 9 no acudieron a la cita. En la valoración por otorrinolaringología, 62 fueron normales y 7 no acudieron; en la valoración por neurología se encontraron 34 normales, 27 aún pendientes de evaluar, 7 que no asistieron y uno anormal en su evaluación.

\section{DISCUSIÓN}

Los reportes de investigación clínica, epidemiológica y de laboratorio confirman que durante la gestación la infección por ZIKV atraviesa la barrera placentaria, afectando el desarrollo embrionario, causando microcefalia y afectaciones severas en el desarrollo cerebral en el neonato, por lo que se considera una enfermedad teratogénica ${ }^{1-5}$. Respecto a la microcefalia en México, la incidencia estimada antes de la introducción del ZIKV fue de 3.7/100,000 nacimientos
Tabla 2. Razón de momios de casos y controles. Razón de probabilidad de presentarse microcefalia al nacer

\begin{tabular}{lccc}
\hline & Microcefalia & $\begin{array}{c}\text { Sin } \\
\text { microcefalia }\end{array}$ & Total \\
\hline Expuestos al Zika & 7 & 62 & 69 \\
No expuestos al Zika & 5 & 133 & 138 \\
Total & 12 & 195 & 207 \\
Odds ratio & 3 & & \\
IC 95\% & $0.91-9.8$ & & \\
Fisher & 0.06 & & \\
\hline
\end{tabular}

IC: intervalo de confianza.

(IC [intervalo de confianza] 95\%: 3.34-4) y posterior a la introducción de este virus en México, la estimación acumulativa es de 11.5/100,000 nacimientos (IC 95\%: 10.4-12.6), lo cual representa un incremento de 3 veces en los casos de microcefalia (riesgo relativo [RR]: 2.9; IC 95\%: 2.3-3.6) . Este incremento en la microcefalia ya se documentó en los registros nacionales en Brasil y Colombia, con tasas porcentuales elevadas después de la introducción del ZIKKV3,8. En Ciudad Mante, Tamps., sitio de este estudio, hace años hubo un brote de fiebre por dengue y ahora se han presentado casos de Zika.

Los resultados del presente estudio muestran que el $10 \%$ de los casos con exposición a ZIKV presentó microcefalia comparado con el $3.6 \%$ en los controles. La razón de momios o de asociación de microcefalia al nacer en los casos fue de 3 , es decir, número de veces la razón de probabilidad de presentarse microcefalia en el niño expuesto al ZIKV gestacional, aunque sin significancia estadística (Fisher, $p=0.06$ ). En nuestra casuística, en que 7 casos expuestos a ZIKV tuvieron microcefalia y en el resto el PC resultó normal, el ultrasonido transfontanelar se realizó en 58 neonatos. Un caso con microcefalia tuvo alteración en la neuroimagen, con agenesia de cuerpo calloso e hidrocefalia del tercer ventrículo. En 7 casos sin microcefalia se encontró dilatación ventricular de las astas anteriores. Algo relativamente semejante aconteció en $\mathrm{Brasil}^{9}$, en donde se reportaron 13 casos de niños con evidencia de infección por ZIKV por determinación en líquido cefalorraquídeo o sérico. De ellos, ninguno tuvo microcefalia, aunque sí tuvieron anormalidades estructurales como disminución del volumen cerebral, malformación cortical, hipoplasia cerebelar y cuerpo calloso, ventriculomegalia, calcificaciones e incremento en el espacio extraaxial del líquido cefalorraquídeo. Concluyeron los autores que la microcefalia no es un sello esencial del 
Tabla 3. Razón de momios de los casos y controles. Razón de probabilidad respecto a infección de la madre por el Zika en el primer semestre de gestación y el desarrollo de microcefalia

\begin{tabular}{lccc}
\hline & Microcefalia & $\begin{array}{c}\text { Sin } \\
\text { microcefalia }\end{array}$ & Total \\
\hline Infección $\leq 27$ SDG & 6 & 20 & 26 \\
Infección > 27 SDG & 1 & 42 & 43 \\
Total & 7 & 62 & 69 \\
Odds ratio & 12.6 & & \\
IC 95\% & $1.4-111$ & & \\
Fisher & 0.01 & & \\
\hline
\end{tabular}

SDG: semanas de gestación; IC: intervalo de confianza.

síndrome de Zika congénito; los bebés con PC normal tienen anomalías cerebrales asociadas a la infección por ZIKV, como ocurrió en nuestro estudio, y pueden desarrollar microcefalia posterior al nacimiento.

Lo anterior llama a reflexión, en el paciente con antecedente de Zika en la madre durante la gestación y que tenga PC normal se debe dar seguimiento a mediano y largo plazo a fin de corroborar esta hipótesis. Lo que no se logró establecer en los casos del presente estudio es la presencia de calcificaciones basales o subcorticales y de otras áreas cerebrales, como se menciona en la literatura ${ }^{1,3,5,9-10}$, sin tener explicación alguna del por qué en nuestros casos no se presentaron calcificaciones.

La correlación entre la infección por el ZIKV, principalmente en los primeros 6 meses de la gestación, y la presencia de microcefalia parece, de hecho, existir ${ }^{10}$. En nuestro caso, los neonatos cuyas madres se infectaron durante el primer semestre $(S D G \leq 27)$ fueron 26/69; de ellos, 6 de los 7 con microcefalia eran neonatos cuyas madres se infectaron antes de las 27 SDG. La razón de momios fue de 12.6 (IC 95\%: 1.4-111; Fisher, $p=0.01$ ) (Tabla 3). Es decir, si la madre se infecta antes de las 27 SDG hay una razón de probabilidad 12 veces mayor de presentarse microcefalia en el neonato respecto a las que se infectan después de las 27 SDG.

\section{CONCLUSIONES}

- Existió microcefalia en los neonatos hijos de madres que se infectaron por ZIKV en la gestación.

- La razón de asociación (probabilidad) de microcefalia en hijos de madres con Zika en la gestación fue 3 veces mayor que en los hijos de madres que no tuvieron Zika.

- La razón de asociación (probabilidad) de microcefalia fue 12 veces mayor en los neonatos cuyas madres se infectaron por ZIKV en el primer semestre del embarazo.

- La tasa de microcefalia en los hijos de madres con Zika en la gestación fue del 10\%.

- Se encontraron alteraciones anatómicas cerebrales en los hijos de madres con Zika en la gestación, aunque no presentaran microcefalia, por lo que la ausencia de microcefalia no es excluyente de afectación cerebral y debe realizarse ultrasonido transfontanelar a todo neonato cuya madre tuvo infección por ZIKV en la gestación.

\section{LIMITACIONES}

El presente estudio comparó a los neonatos hijos de madres que fueron positivas al ZIKV mediante la prueba RT-PCR Zika con los controles, que fueron los hijos de madres que refirieron no haber presentado proceso febril durante el embarazo, es decir, solamente se indagó si tuvo un proceso febril, aunque no se realizó la prueba RNA RT-PCR Zika. Lo anterior fue debido a la limitante de la disposición de la prueba RNA RT-PCR Zika, ya que esta prueba se realiza cuando las embarazadas presentan un proceso febril. Por ello, queda la duda del sesgo probable de que hubo mujeres en ese grupo control que pudieran haberse infectado con ZIKV y haber cursado asintomáticas, ya que, como se comentó anteriormente, 4 de cada 5 mujeres embarazadas permanecen asintomáticas durante la enfermedad del Zika ${ }^{2-4}$. Por otro lado, en ambos grupos, casos y controles, se consideró clínicamente que no tuvieran afectaciones por el complejo TORCH, cuyas pruebas no se realizan sistemáticamente debido al alto costo, lo cual igualmente deja en la incertidumbre el descartar alguna infección subclínica. Por lo anterior puede ser cuestionable el estudio.

\section{FINANCIAMIENTO}

La presente investigación no ha recibido ayudas específicas provenientes de agencias del sector público, sector comercial o entidades sin ánimo de lucro. 


\section{CONFLICTO DE INTERESES}

Los autores declaran no tener conflicto de intereses.

\section{RESPONSABILIDADES ÉTICAS}

Protección de personas y animales. Los autores declaran que para esta investigación no se han realizado experimentos en seres humanos ni en animales.

Confidencialidad de los datos. Los autores declaran que han seguido los protocolos de su centro de trabajo sobre la publicación de datos de pacientes.

Derecho a la privacidad y consentimiento informado. Los autores declaran que en este artículo no aparecen datos de pacientes.

\section{BIBLIOGRAFÍA}

1. Matos-Alviso LJ, Santos-Calderón LA, Reyes-Hernández KL, Reyes-Gómez U, Santamaría-Arza C, López-Cruz G, et al. Síndrome congénito por virus zika, conceptos básicos. Salud Quintana Roo. 2017;10(37):33-6.

2. Sánchez-González JM, Ramos-Remus C, Jácome-Sánchez B, García-Ortiz R, Flores-Ramos J, Santoscoy-Hernández F. Virus Zika en México. Rev Latinoam Patol Clin Med Lab. 2016;63(1):4-12.

3. Alvarado-Socarras JL. Zika en neonatos: todo no está dicho. Salud UIS. 2016 48(2):160-2.

4. Kably-Ambe A. Enfermedad por virus Zika. Ginecolo Obstet Mex. 2016; $84(2): 1-2$.

5. Schuler L, Ribeiro E, Feitosa I, Horovitz D, Calvalcanti D, Pessoa A, et al. Posible vínculo entre la infección por el virus Zika y la microcefalia - Brasil, 2015. MMWR. 2016;65:1-4.

6. Olsen IE, Groverman S, Lawson ML, Clark R, Zemel B. New intrauterine growth curves based in U.S. data. Pediatrics. 2010;125(2):e214-e244.

7. Hernández-Ávila JE, Palacio-Mejía LS, López-Gatell H, Alpuche-Aranda CM, Molina-Vélez D, González-González L, et al. Zika virus infection estimates, Mexico. Bull Word Health Organ. 2018:96:306-13.

8. Candelo E, Caicedo G, Feinstein M, Pachajoa H. Microcephaly in Colombia before the Zika outbreak: A systematic literature review. Biomedica. 2018;38:127-34.

9. Van der Linder V, Pessoa A, Dobyns W, Barkovich A, van der Linder H, Rolim E. Description of 13 infants born during October 2015 - January 2016 with congenital Zika virus infection without microcephaly at birth Brazil. MMWR. 2016;65(47):1343-8.

10. Leyser M, Halpem R. Virus Zika: Una amenaza potencial e inesperada a la salud y al desarrollo del niño. Resid Pediátr. 2016;6(2):63-4. 